\title{
Effects of ACE inhibitors on coronary haemodynamics and angina pectoris
}

\author{
M K Davies
}

Angiotensin II is a potent vasoconstrictor of both coronary and peripheral vasculature; it increases myocardial contractility, promotes myocardial hypertrophy, and possibly contributes to the process of atherosclerosis. In addition, the renin-angiotensin system and the sympathetic nervous system are interdependent, each stimulating the activity of the other. Angiotensin II enhances the activity of the sympathetic nervous system by facilitating the release of noradrenaline $\mathrm{e}^{1-4}$ and by interfering with its neuronal reuptake. ${ }^{56}$ Angiotensin II has important central and peripheral vagolytic effects. ${ }^{7-10}$ Vasodilatation and decreased fluid retention reduce preload, afterload, heart size, and left ventricular wall stress, thereby reducing myocardial oxygen demand. Similarly, reductions in the left ventricular hypertrophy associated with hypertension and heart failure and reductions in the positive inotropic effects of angiotensin II could contribute to reduced myocardial oxygen demand. A reduction in sympathetic and increase in parasympathetic tone at rest and on exercise, due to inhibition in activity of both the renin-angiotensin system and the sympathetic nervous system by angiotensin converting enzyme (ACE) inhibitors, will reduce heart rate, or the reflex tachycardia usually associated with peripheral vasodilatation, and thereby reduce the ratepressure (double) product. A concurrent reduction in vasoconstriction mediated by angiotensin II at the coronary vascular bed should result in coronary vasodilatation and an improvement in myocardial oxygen supply. Despite these diverse potential mechanisms affecting both myocardial oxygen demand and supply beneficially, a consistent and clinically significant anti-ischaemic effect of ACE inhibition has been difficult to show.

ACE inhibitors improve prognosis in all grades of symptomatic heart failure, reducing mortality from progressive heart failure and sudden death. ${ }^{11-14}$ Sudden death is often presumed to be arrhythmic in origin, but most patients with heart failure have complex ventricular ectopic activity on Holter monitoring. ${ }^{15}$ Although the presence of these arrhythmias is related to prognosis in some studies, their predictive accuracy is generally weak. ${ }^{12}$ 16-19 There are few large postmortem studies in heart failure, but the data available suggest that the arrhythmias associated with sudden death in these patients are often the manifestation of some intercurrent coronary or pulmonary thrombotic event. ${ }^{19}$ The reduction in incidence of sudden death observed after ACE inhibitors in heart failure may be due in part therefore to a beneficial effect on the coronary circulation, atherogenesis, or the thrombotic process. ${ }^{20}$ Both the recent SOLVD treatment ${ }^{13}$ and $\mathrm{SAVE}^{21}$ studies have shown a reduction in the rate of recurrent infarction in patients with heart failure or with impaired left ventricular function after myocardial infarction who have been treated with ACE inhibitors. Thus, indirect data are available to suggest that ACE inhibitors have antiischaemic effrects that could account for some of their beneficial therapeutic and prognostic effects.

\section{Effects of ACE inhibitors in patients with stable angina}

The effects of ACE inhibitors on coronary vascular tone was studied by Karsch et al in 12 patients with coronary heart disease and exertional angina. ${ }^{22}$ Central haemodynamic measurement and coronary angiography were carried out during control pacing and during angina induced by rapid atrial pacing before and after ACE inhibition with intravenous captopril. At rest and during ischaemia captopril resulted in coronary vasodilatation at the site of coronary atherosclerotic narrowing, increasing coronary artery diameter by $0.1 \mathrm{~mm}$ at rest and by $0.2 \mathrm{~mm}$ during ischaemia. These changes were associated with a fall in left ventricular end diastolic pressure and peripheral vasodilatation. Despite these favourable haemodynamic changes, however, only one patient experienced a significant reduction in angina, captopril having no significant effect on coronary artery diameter in the non-diseased segments. Ikram et al also used intravenous captopril and atrial pacing to examine the effects on angina threshold and systemic and coronary haemodynamics in 12 patients with documented coronary artery disease. ${ }^{23}$ Captopril resulted in an increased time to angina and increased paced heart rate for the development of angina, with a trend towards increased coronary blood flow (229 to $296 \mathrm{ml} / \mathrm{min}, \mathrm{P}=0 \cdot 11$ ) and decreased coronary vascular resistance (53 to $47 \mathrm{dyn} \cdot \mathrm{s} \cdot \mathrm{cm}^{-5} / 1000$, $P=0 \cdot 11$.

The clinical effects of ACE inhibitors in angina pectoris were investigated by Gibbs et al in 12 patients with chronic stable angina. ${ }^{24}$ In a two week double blind placebo controlled study the effects of oral enalapril on angina frequency and treadmill exercise 
testing were determined. Enalapril reduced resting and exercise double product (each by about $10 \%$ ) by reducing systolic blood pressure at rest and on exercise without an effect on heart rate. In the group as a whole, however, the frequency of angina and consumption of glyceryl trinitrate was not improved with enalapril. On formal exercise testing enalapril increased exercise duration by $43 \mathrm{~s}$ (from $466 \mathrm{~s}$ to $509 \mathrm{~s}$ ) and exercise duration to ST segment depression $(0.1 \mathrm{mV})$ by $42 \mathrm{~s}$ (from $345 \mathrm{~s}$ to $387 \mathrm{~s}$ ). However, interpatient variability was considerable, with four patients showing an increase in total exercise time of more than $20 \%$ with enalapril and two patients showing a marked reduction in exercise capacity and an increase in angina frequency. Thus, although ACE inhibitors seemed to reduce myocardial ischaemia in some patients, deterioration was evident in a large proportion.

The effects of ACE inhibition on myocardial ischaemic episodes has also been examined using ambulatory ST segment monitoring over 24 hours. In a study of 11 normotensive patients with angiographically proved coronary artery disease Thurmann et al showed that the number of angina attacks and ischaemic episodes was not significantly reduced after treatment with the ACE inhibitor benazepril. ${ }^{25}$ On formal exercise testing these patients' exercise double product and maximal exercise induced ST segment depression were not improved. Interpatient variability was again considerable, with six patients improving (as assessed by maximal ST segment depression) and three patients manifesting worsening of ischaemia. In a similar study by Klein et al in 29 patients with chronic stable angina benazepril did not alter exercise time or improve exercise induced ischaemia. ${ }^{26}$ Although the number of episodes of ST segment depression on ambulatory monitoring and the total ischaemic burden was reduced from 1549 minutes in the placebo group to 879 minutes in the benazepril group, these changes were not significant. Benazepril did not reduce angina frequency or consumption of glyceryl trinitrate. In a more recent study on 34 patients with chronic stable angina benazepril again failed to improve total exercise duration or exercise time to ST segment depression of $1 \mathrm{~mm} \cdot{ }^{27}$ On ambulatory monitoring for 48 hours the number of episodes of ST segment depression $(>1 \mathrm{~mm})$ did not change significantly, and, although there were falls in total ischaemic burden and the number of episodes of silent ischaemia, these changes were not significant. However, benazepril treatment resulted in a significant reduction in the maximal depth of ST segment depression and significantly altered the circadian rhythm of myocardial ischaemia.

The MERCATOR study assessed the effects of cilazapril on the prevention of angiographic restenosis in 595 patients after percutaneous transluminal coronary angioplasty. ${ }^{28}$ Cilazapril did not improve any objective variable on exercise testing (although signifi- cantly fewer patients developed chest pain during exercise: 74 given placebo $v 42$ given cilazapril, $\mathbf{P}=0.03$ ). In another study of 12 patients cilazapril did not improve exercise time to angina. ${ }^{29}$ Similarly, enalapril did not improve exercise time to development of angina in a group of 12 patients with stable angina after one week's treatment. ${ }^{30}$

Thus in chronic stable angina several studies, each of small numbers of patients, have failed to show a convincing antiischaemic effect with ACE inhibitors whether this is assessed by symptoms, exercise testing, or ambulatory ST segment monitoring. Although beneficial systemic and coronary haemodynamic effects can occur, which might be expected to improve myocardial ischaemia, individual patient responses are unpredictable and the use of ACE inhibitors may cause a deterioration in angina in some patients.

\section{Effects of ACE inhibitors on unstable angina}

In patients with unstable angina cardiac sympathetic activity is significantly increased compared with that in patients with stable angina. Tritiated noradrenaline infusions in patients undergoing coronary angiography show that cardiac noradrenaline spillover and coronary sinus noradrenaline concentration are increased in patients who have had unstable angina within the preceding three months compared with those with stable angina. ${ }^{31}$ This suggests that the increase in sympathetic activity may be sustained and persist for several months after a period of unstable angina. A similar increase in cardiac sympathetic overactivity has been shown in another study of unstable angina, but persistent abnormalities were not found as patients with inactive unstable angina (unstable angina occurring 8-12 weeks previously but no angina for at least four weeks) had no change in cardiac noradrenaline spillover compared with controls. ${ }^{32}$ In this study a correlation was found between the number of silent ischaemic episodes or the overall duration of ischaemia and noradrenaline spillover, suggesting that sympathetic overactivity might be a determinant of ischaemia, though a causal relation should not be assumed. A single dose of captopril (25 mg by mouth) attenuated sympathetically mediated increases in coronary vascular resistance induced by the cold pressor test or the diving reflex in a study of nine patients with coronary artery disease. ${ }^{33}$ The predominant anti-ischaemic effect of ACE inhibitors may reside in their ability to reduce sympathetic tone rather than the inhibition of the other diverse haemodynamic and neuroendocrine effects of angiotensin II.

\section{Effects of ACE inhibitors in patients} with angina and hypertension

ACE inhibitors are effective antihypertensive agents that reduce blood pressure and left ventricular hypertrophy. The reduction in blood pressure is not associated with a reflex 
tachycardia and therefore reductions in ratepressure product result. This effect profile is of potential benefit in patients with hypertension and coronary artery disease, a common association. ${ }^{34}$ Few studies have examined the effects of ACE inhibitors on coronary haemodynamics in patients with hypertension and coronary artery disease. Daly et al reported the acute effects of oral captopril in a group of eight patients. ${ }^{35}$ Captopril reduced the ratepressure product, coronary blood flow, and myocardial oxygen consumption. Although the only significant change was in the ratepressure product, the changes in coronary blood flow and myocardial oxygen consumption tended to parallel the decrease in double product.

Akhras and Jackson compared the effects of captopril treatment and placebo in a single blind study of 18 patients with hypertension and angina due to coronary artery disease. ${ }^{36}$ Captopril had a significant antihypertensive effect, increased the time to ST segment depression $(1 \mathrm{~mm})$ from $188 \mathrm{~s}$ to $364 \mathrm{~s}$, and reduced the maximum ST segment depression from $2.5 \mathrm{~mm}$ to $1.2 \mathrm{~mm}$. Exercise duration was increased from $310 \mathrm{~s}$ to $461 \mathrm{~s}$. In addition to these objective criteria of myocardial ischaemia, the number of angina attacks was reduced from $17 \cdot 6$ to $4 \cdot 0$. In another study perindopril significantly improved exercise induced ischaemia in a group of 51 patients with ischaemic heart disease and hypertension and reduced angina frequency (from 6 to $2 \cdot 3$ per week). ${ }^{37}$

\section{Effects of ACE inhibitors on coronary haemodynamics in heart failure}

Intracoronary enalaprilat was used in a study of 16 patients with dilated cardiomyopathy to differentiate between direct coronary effects and effects secondary to systemic vasodilatation. ${ }^{38}$ After bilateral coronary infusion enalaprilat increased coronary blood flow by $19 \%$ and reduced coronary artery resistance by $18 \%$. This was associated with an increase in coronary sinus oxygen content and pressure. However, enalaprilat also caused a fall in cardiac index, ejection fraction, and the ratio of end systolic stress to end systolic volume. Thus the coronary vasodilator and negative inotropic effects were consistent, in this study, with a reduction in angiotensin II mediated coronary vasoconstriction and positive inotropic effect. The fall in ejection fraction and other indices of cardiac function in this study are opposite to the effects observed in the heart failure trials, but in these instances the oral administration of the ACE inhibitor results in simultaneous systemic vasodilatation, which offsets any direct adverse myocardial effect.

A $20 \%$ increase in coronary blood flow associated with a fall in filling pressures and double product occurred in a study of short term enalaprilat treatment in patients with severe congestive heart failure ${ }^{39}$ Most studies have noted, however, that coronary vascular resistance declines somewhat less than the general systemic vascular resistance during ACE inhibition; as the fall in coronary perfusion pressure- that is, blood pressureis greater than the fall in coronary resistance, coronary blood flow tends to fall. The reason why coronary resistance falls less than in other circulations is probably because of autoregulation in response to reduced myocardial oxygen demand caused by reductions in heart rate, preload, and afterload. Thus, oral cilazapril given short term produced coronary vasodilatation with a fall in double product and improved myocardial lactate metabolism but no change in coronary blood flow in patients with heart failure due to ischaemic heart disease or congestive cardiomyopathy. ${ }^{40}$ A decrease in coronary blood flow (by 13\%) after short term oral captopril in 11 patients with heart failure was found in a study by Rouleau et al. ${ }^{41}$ This decrease was considerably less than the decrease in double product $(27 \%)$ and myocardial oxygen consumption $(19 \%)$. Similarly, a decrease in coronary blood flow $(17 \%, \mathrm{NS})$ was observed by Halperin et al without a change in coronary vascular resistance, but coronary arteriovenous oxygen difference and myocardial oxygen consumption were unchanged, presumably because of the concomitant reductions in preload and afterload. ${ }^{42}$

Measures of global coronary blood flow may be irrelevant to the problem of angina, in which regional flow is far more important. Coronary arteriolar tone is usually low in regions of myocardium subtended by a severe epicardial coronary stenosis and dilatation may not increase much after ACE inhibition. $\mathrm{ACE}$ inhibitors have the potential to reduce coronary vascular resistance in territories supplied by normal epicardial coronary arteries, "stealing" blood away from ischaemic zones $^{43}$ and worsening regional ischaemia.

\section{Effects of ACE inhibitors on angina in} patients with heart failure

In a double blind placebo controlled crossover study the effects of oral captopril on symptoms and exercise test results were determined in 18 patients with chronic heart failure and angina. ${ }^{43}$ Treatment resulted in a worsening of angina symptoms as assessed by visual analogue scores and use of glyceryl trinitrate. Exercise performance tended to deteriorate with ACE inhibition, with an increase in the number of patients stopping exercise because of developing angina.

Effects of ACE inhibitors on subsequent ischaemic events in patients with previous myocardial infarction, left ventricular dysfunction, or heart failure Several clinical trials have shown that ACE inhibitors have beneficial effects on recurrent ischaemic events in patients after myocardial infarction and in patients with chronic left ventricular systolic dysfunction with or without heart failure. The results of these studies with respect to death and recurrent infarction 
is dealt with at greater length by Hall and Ball in this supplement, ${ }^{44}$ but I will examine the results of these trials to identify possible effects of treatment on the occurrence of angina.

The SMILE study (survival of myocardial infarction long-term evaluation) examined the effects of the ACE inhibitor zofenopril on subsequent cardiac events in 204 patients after myocardial infarction. ${ }^{45}$ There was a small (non-significant) reduction in mortality at one year and the number of fatal reinfarctions was not reduced, though the incidence was low in each group (two patients in zofenopril group, two in control group). However, the incidence of early and late recurrence of angina were both reduced in the ACE inhibitor group $(8.9 \%$ v $27 \cdot 1 \%$ and $9.8 \% v$ $21.7 \%$ respectively). In the SOLVD prevention trial in patients with asymptomatic left ventricular dysfunction enalapril reduced the relative risk of subsequent unstable angina by $14 \% .{ }^{46} 47$ In the SOLVD treatment trial in patients with mild to moderate heart failure similar results were seen, the relative risk of developing unstable angina being reduced by $27 \%{ }^{13} 47$

Further objective evidence of a reduction in subsequent ischaemia after myocardial infarction was obtained in a recent study by Sogaard et al in 64 patients followed up for six months. ${ }^{48}$ Captopril resulted in a reduction in ST segment depression on ambulatory monitoring and on exercise testing. The effects on ischaemic indices gradually increased over the follow up period. A similar effect was observed in other ACE inhibitor studies-that is, SAVE and SOLVD prevention-in which the coronary event rates diverged little until 12-18 months.

Not all studies have shown these beneficial effects, however. In the Nordic enalapril exercise trial (a subtrial of CONSENSUS II) exercise testing at one and six months after myocardial infarction in 327 patients did not show any benefit from ACE inhibition with respect to the frequency of ST segment depression or angina as the limiting symptom. ${ }^{49} \mathrm{~A}$ similar study in a smaller group (99 patients) also showed no benefit from captopril treatment on the occurrence of ischaemia on exercise testing at one year..$^{50}$

Finally, the anti-ischaemic mechanisms of ACE inhibitors may have accounted for and contributed to the observed improvements in sudden death reported in other trials-that is, V-HeFT II-as sudden death may be related to ischaemic intercurrent cardiac events (recent myocardial infarction and acute coronary thrombosis). ${ }^{19}$

\section{Conclusions}

ACE inhibitors should have, at least theoretically, significant anti-ischaemic properties. ACE inhibitors do have anti-ischaemic properties in some patients with angina, hypertension, and concomitant coronary artery disease, as well as in patients with heart failure due to previous hypertension, congestive cardiomyopathy, or ischaemic heart disease. The main anti-ischaemic effects may be indirect and related to reductions in left ventricular pressure, cavity size, and wall stress and to concomitant reductions in sympathetic tone rather than overriding direct primary effects on coronary haemodynamics. The observed responses are often weak and unpredictable. Coronary steal phenomena might be important in negating the benefits of ACE inhibition and explain why some patients deteriorate in terms of developing ischaemia or angina symptoms.

A clear distinction must be made between the short term effects of ACE inhibitors on ischaemia and angina and their potential for modifying the natural history of atheromatous disease, a much more long term process.

1 Zimmerman BG, Whitmore L. Effect of angiotensin and phenoxybenzamine on release of noradrenaline in vessels during sympathetic nerve stimulation. International fournal of Neuropharmacology 1967;6:27-38.

2 Zimmerman BG, Gisslen J. Pattern of renal vasoconstriction and transmitter release during sympathetic stimulation in the presence of angiotensin and cocaine. f Pharmacol Exp Ther 1968;163:320-9.

3 Zimmerman BG. Actions of angiotensin on adrenergic nerve endings. Fed Proc 1978;37:199-202.

4 Hughes J, Roth RH. Evidence that angiotensin enhances transmitter release during sympathetic nerve stimulation. Br f Pharmacol 1971;41:239-55.

5 Palaic D, Khairallah PA. Inhibition of noradrenaline uptake by angiotensin. 7 Pharm Pharmacol 1967;19:396-7.

6 Peach MJ, Bumpus FM, Khairallah PA. Inhibition of Peach MJ, Bumpus FM, Khairallah PA. Inhibition of
noradrenaline uptake in hearts by angiotensin II and noradrenaline uptake in hearts by angiotensin
analogs. F Pharmacol Exp Ther 1969;167:291-9.

7 Scroop GC, Lowe RD. Efferent pathways of the cardiovascular response to vertebral artery infusions of angiotensin in the dog. Clin Sci 1969;37:605-19.

8 Lumbers ER, McCloskey DI, Potter EK. Inhibition by angiotensin II of baroreceptor-evoked activity in cardiac vagal efferent nerves in the dog. $\mathcal{F}$ Physiol (Lond) 1979;294:69-80.

9 Potter EK. Angiotensin inhibits action of vagus nerve at the heart. Br $\mathcal{F}$ Pharmacol 1982;75:9-11.

10 Goldsmith SR, Hasking GJ. Effect of a pressor infusion of angiotensin II on sympathetic activity and heart rate in normal humans. Circ Res 1991;68:263-8.

11 CONSENSUS Trial Study Group. Effects of enalapril on mortality in severe congestive heart failure. $N \mathrm{Engl} \mathcal{F} \mathrm{Med}$ 1987;316:1429-35.

12 Cohn JN, Johnson G, Ziesche S, et al. A comparison of enalapril with hydralazine-isosorbide dinitrate in the
treatment of chronic congestive heart failure. $N$ Engl $\mathcal{F}$ Med 1991;325:303-10.

13 SOLVD Investigators. Effect of enalapril on survival in patients with reduced left ventricular ejection fractions patients with reduced left ventricular ejection fractions and cong $293-302$.

14 Fonarow GC, Chelimsky-Fallick C, Stevenson LW, et al. Effect of direct vasodilatation with hydralazine versus angiotensin converting enzyme inhibition with captopril on mortality in advanced heart failure: the $\mathrm{Hy}-\mathrm{C}$ trial. f Am Coll Cardiol 1992;19:842-50.

15 Francis GS. Development of arrhythmias in the patient with congestive heart failure: pathophysiology, prevalence and prognosis. Am f Cardiol 1986,57:3-7B.

16 Cohn JN, Archibald DG, Ziesche S, et al. Effect of vasodilator therapy on mortality in chronic congestive heart failure: results of a Veterans Administration cooperative study (V-HeFT I). $N$ Engl f Med 1986;314: $1547-52$.

17 Cohn JN, Johnson GR, Shabeti R, et al. Ejection fraction, peak exercise oxygen consumption, cardiothoracic ratio, ventricular arrhythmias, and plasma norepinephrine as determinants of prognosis in heart failure. Circulation 1993;87(suppl VI):VI-5-16.

$18 \mathrm{Kjekshus} \mathrm{J.} \mathrm{Arrhythmias} \mathrm{and} \mathrm{mortality} \mathrm{on} \mathrm{congestive} \mathrm{heart}$ failure. Am F Cardiol 1990;65:42-8I.

19 Luu M, Stevenson WG, Stevenson LW, Baron K, Walden J. Diverse mechanisms of unexpected cardiac arrest in advanced heart failure. Circulation 1989;80: arrest in $1675-80$.

20 Ridker PM, Gaboury CL, Conlin PR, Seely EW, Williams GH, Vaughan DE. Stimulation of plasminogen activator inhibitor in vivo by infusion of angiotensin II. activator inhibitor in vivo by
Circulation 1993;87:1969-73.

21 Pfeffer MA, Braunwald E, Moye LA, et al. Effect of captopril on mortality and morbidity in patients with left captopril on mortality and morbidity in patients with left ventricular dysfunction after
$N$ Engl $₹ \mathrm{Med}$ 1992;327:669-77.

22 Karsch KR, Voelker W, Mauser M. Myocardial and coronary effects of captopril during pacing-induced ischaemia in patients with coronary artery disease. Eur Heart $\mathcal{F}$ 1990;11(suppl B): 157-61. 
23 Ikram H, Low CJ, Shirlaw T, Webb CM, Richards AM, Crozier IG. Antianginal, hemodynamic and coronary
vascular effects of captopril in stable angina pectoris. $\mathrm{Am}$ vascular effects of captopri

24 Gibbs JS, Crean PA, Mockus L, Wright C, Sutton GC, Fox KM. The variable effects of angiotensin converting enzyme inhibition on myocardial ischae
stable angina. $B r$ Heart $\mathcal{f} 1989 ; 62: 112-7$.

25 Thurmann P, Odenthal H-J, Rietbrock N. Converting enzyme inhibition in coronary artery disease: a randomised, placebo-controlled trial with benazepril. f Cardiovasc Pharmacol 1991;17:718-23.

26 Klein WW, Khurmi NS, Eber B, Dusleag J. Effects of benazepril and metoprolol OROS alone and in combination on myocardial ischemia in patients with chronic stable angina. $\mathcal{f} \mathrm{Am}$ Coll Cardiol 1990;16: 948-56.

27 Ikram H, Low CJ, Shirlaw TM, et al. Angiotensin converting enzyme inhibition in chronic stable angina: effects on myocardial ischaemia and comparison with nifedipine. Br Heart $\mathcal{f}$ 1994;71:30-3.

28 MERCATOR Study Group. Does the new angiotensin converting enzyme inhibitor cilazapril prevent restenosis after percutaneous transluminal angioplasty? Circulation 1992;86:100-10.

29 Jackson NC, Lee PS, Reynolds G, Taylor SH. A study of ACE inhibition in angina [abstract]. Eur Heart $f$ 1987;8(suppl 2):88.

30 Abrams J, LeTourneau J. Angiotensin converting enzyme inhibition in the therapy of angina pectoris [abstract]. Cardiovascular Drugs and Therapy 1987;1:209.

31 McCance AJ, Thompson PA, Forfar JC. Increased cardiac sympathetic nervous system activity in patients with unstable coronary heart disease. Eur Heart $\mathcal{F}$ 1963;14: $751-7$

32 Neri Serneri GG, Boddi M, Arata L, et al. Silent ischemia in unstable angina is related to an altered cardiac norepinephrine handling. Circulation 1993;87:1928-37.

33 Perondi R, Saino A, Tio RA, et al. ACE inhibition attenuates sympathetic coronary vasoconstriction in patients with coronary artery disease. Circulation 1992; 85:2004-13.

34 Otterstad JE, Davies M, Ball SG, et al. Left ventricular hypertrophy and myocardial ischaemia in hypertension. The THAMES study. Eur Heart $\mathcal{f}$ 1993;14:1622-8.

35 Daly P, Rouleau J-L, Cousineau D, Burgess JH. Acute effects of captopril on the coronary circulation of patients with hypertension and angina. Am $f$ Med 1984;76: 111-5.

36 Akhras F, Jackson G. The role of captopril as single therapy in hypertension and angina pectoris. Int $\mathcal{f}$ Cardiol in hypertension

37 Stompe KO, Overlack A. A new trial of the efficacy, tolerability, and safety of angiotensin converting enzyme inhibition in mild systemic hypertension with concomitant diseases and therapies. Am $\mathcal{f}$ Cardiol 1993;71: comitan

38 Foult J-M, Tavolaro O, Antony I, Nitenberg A. Direct myocardial and coronary effects of enalaprilat in patients with dilated cardiomyopathy: assessment by a bilateral intracoronary infusion technique. Circulation 1988;77: 337-44.

39 Dietz R, Haberbosch W, Susselbeck T, Fischer T, Hauck S, Osterziel KJ. Modulation of coronary circulation and the cardiac matrix by the renin-angiotensin system. Eur Heart f 1991;12(suppl F):107-11.

40 Kiowski W, Zuber M, Elsasser S, Erne P, Pfisterer M, Burkhart F. Coronary vasodilatation and improved myocardial lactate metabolism after angiotensin converting enzyme inhibition with cilazapril in patients with congestive heart failure. Am Heart f 1991;122:1382-8.

41 Rouleau J-L, Chatterjee K, Benge W, Parmley W, Hiramatsu B. Alterations in left ventricular function and coronary hemodynamics with captopril, hydralazine and prazosin in chronic ischemic heart failure: a comparative study. Circulation 1982;65:671-8.

42 Halperin JL, Faxon DP, Creager MA, et al. Coronary hemodynamic effects of angiotensin inhibition by captopril and teprotide in patients with congestive heart captopril and teprotide in patients with

43 Cleland JG, Henderson E, McLenachan J, Findlay IN, Dargie HJ. Effect of captopril, an angiotensin-converting enzyme inhibitor, in patients with angina pectoris and heart failure. $7 \mathrm{Am}$ Coll Cardiol 1991;17:733-9.

44 Ball SG, Hall AS. What to expect from ACE inhibitors after myocardial infarction. $\mathrm{Br}$ Heart $\mathcal{f}$ 1994;72(3) (suppl):S70-4

45 Ambrosioni E, Borghi C, Magnani B. Early treatment of acute myocardial infarction with angiotensin-converting enzyme inhibition: safety considerations. $A m \mathcal{F}$ Cardiol 1991;68:101-10D.

46 SOLVD Investigators. Effect of enalapril on mortality and the development of heart failure in asymptomatic patients with reduced left ventricular ejection fractions. $N$ Engl f Med 1992;327:685-91.

47 Yusuf S, Pepine CJ, Garces C. Effect of enalapril on myocardial infarction and unstable angina in patients with low ejection fractions. Lancet 1992;340:1173-8.

48 Sogaard P, Gotzsche C-O, Ravkilde J, Thygesen K. Effects of captopril on ischemia and dysfunction of the left ventricle after myocardial infarction. Circulation 1993;87: ventricle

49 Dickstein K, Aarsland T. Effect on exercise performance of enalapril therapy initiated early after myocardial enalapril therapy initiated early after
infarction. $\mathcal{F} \mathrm{Am}$ Coll Cardiol 1993;22:975-83.

50 Ray SG, Pye M, Oldroyd KG, et al. Early treatment with captopril after acute myocardial infarction. Br Heart $\mathcal{f}$ 1993;69:215-22. 